\title{
Erratum to: Relationship between individual and group learning in a marine teleost: A case study with sea bass under self-feeding conditions
}

\author{
David Benhaïm $^{1,2}$ - Sébastien Ferrari ${ }^{1,2}$ - Tatiana Colchen ${ }^{3}$ - Béatrice Chatain ${ }^{4}$. \\ Marie-Laure Bégout ${ }^{5}$
}

Published online: 5 June 2017

(C) Psychonomic Society, Inc. 2017

Erratum to: Learn Behav

DOI: $10.3758 / \mathbf{s} 13420-017-0266-1$

The Given Name and Family Name of the second author are inverted. The correct order is Sébastien Ferrari. The original article was corrected.

The online version of the original article can be found at http://dx.doi.org/ 10.3758/s13420-017-0266-1

David Benhaïm

david.benhaim@cnam.fr

Laboratoire universitaire des sciences appliquées de Cherbourg, Normandie Univ, UNICAEN, LUSAC, 50100 Cherbourg, France

2 Conservatoire National des Arts et Métiers. Intechmer, 50100 Cherbourg, France

3 Université de Lorraine, Unité de Recherche Animal et Fonctionnalités des Produits Animaux, USC INRA 340, 54506 Vandoeuvre-lès-Nancy, Cedex 09, France

4 Ifremer, UMR 9190 MARBEC, Station Expérimentale d'Aquaculture, Chemin de Maguelone, 34250 Palavas-Les-Flots, France

5 Ifremer, place Gaby Coll, 17137 L'Houmeau, France 